\title{
Potential anti-inflammatory, anti-adhesive, anti/estrogenic, and angiotensin-converting enzyme inhibitory activities of anthocyanins and their gut metabolites
}

\author{
Maria Hidalgo • Sonsoles Martin-Santamaria • Isidra Recio • \\ Concepcion Sanchez-Moreno - Beatriz de Pascual-Teresa • \\ Gerald Rimbach $\cdot$ Sonia de Pascual-Teresa
}

Received: 31 August 2011/Accepted: 13 December 2011/Published online: 5 January 2012

(c) Springer-Verlag 2011

\begin{abstract}
Epidemiological studies have indicated a positive association between the intake of foods rich in anthocyanins and the protection against cardiovascular diseases. Some authors have shown that anthocyanins are degraded by the gut microflora giving rise to the formation of other breakdown metabolites, which could also contribute to anthocyanin health effects. The objective of this study was to evaluate the effects of anthocyanins and their breakdown metabolites, protocatechuic, syringic, gallic, and vanillic acids, on different parameters involved in atherosclerosis, including inflammation, cell adhesion, chemotaxis, endothelial function, estrogenic/anti-estrogenic activity, and angiotensin-converting enzyme (ACE) inhibitory activity. From the assayed metabolites, only protocatechuic acid exhibited a slight inhibitory effect on NO production and TNF- $\alpha$ secretion in LPS-INF- $\gamma$-induced macrophages. Gallic acid caused a decrease in the secretion of MCP-1, ICAM-1, and VCAM-1 in endothelial cells. All
\end{abstract}

M. Hidalgo $\cdot$ C. Sanchez-Moreno $\cdot$ S. de Pascual-Teresa $(\bowtie)$ Institute of Food Science, Food Technology and Nutrition (ICTAN), Spanish National Research Council (CSIC), Ciudad Universitaria, José Antonio Novais 10, 28040 Madrid, Spain e-mail: soniapt@ictan.csic.es

S. Martin-Santamaria · B. de Pascual-Teresa

Department of Chemistry, Facultad de Farmacia, Universidad

San Pablo CEU, Boadilla del Monte, 28668 Madrid, Spain

\section{Recio}

Instituto de Investigacion en Ciencias de la Alimentacion (CIAL, CSIC-UAM), Campus de la Universidad Autonoma de Madrid, Nicolas Cabrera, 9, 28049 Madrid, Spain

\section{G. Rimbach}

Institute of Human Nutrition and Food Science,

Division of Food Science, Christian-Albrechts-University Kiel, Hermann-Rodewald-Strasse 6, 24118 Kiel, Germany anthocyanins showed an ACE-inhibitory activity. Delphinidin-3-glucoside, pelargonidin-3-glucoside, and gallic acid showed affinity for ER $\beta$ and pelargonidin and peonidin-3-glucosides for ER $\alpha$. The current data suggest that anthocyanins and their breakdown metabolites may partly provide a protective effect against atherosclerosis that is multi-causal and involves different biochemical pathways. However, the concentrations of anthocyanins and their metabolites, as used in the present cell culture and in vitro assays mediating anti-inflammatory, anti-adhesive, antiestrogenic, and angiotensin-converting enzyme inhibitory activities, were often manifold higher than those physiologically achievable.

Keywords Anthocyanins - Atherosclerosis - Metabolites · Phenolic acids - Estrogen receptor

\section{Introduction}

Polyphenolic substances, such as anthocyanins, exert a great variety of physiological activities responsible for the health effects attributed to some foods, including a reduced risk of cardiovascular diseases. This is partly due to their anti-inflammatory properties (González-Gallego et al. 2010; Landberg et al. 2011; Rotelli et al. 2003), antioxidant and free radical scavenging activities (García-Alonso et al. 2009; Gray and DeWitt 1999; Kahkonen and Heinonen 2003; Matsumoto et al. 2002; Tsuda et al. 1994; Wang et al. 1997), peroxidation inhibition (Tsuda et al. 1996), and estrogenic/anti-estrogenic activity (Cassidy et al. 2003). It has been largely proven that the beneficial potential of polyphenols as part of a healthy diet cannot be only explained by their antioxidant characteristics (Virgili and Marino 2008). 
One of the biological mechanisms by which flavonoids exhibit anti-inflammatory effects appears to be associated with the inhibition of nitric oxide (NO) production (Vallance and Leiper 2002). A critical step in both inflammation and atherosclerosis is the adhesion of circulating monocytes to vascular endothelial cells, which involves vascular cell adhesion molecule-1 (VCAM-1) and intercellular adhesion molecule-1 (ICAM-1). Studies in vitro suggest that flavonoids participate in the prevention and attenuation of inflammatory diseases by decreasing ICAM-1 and VCAM-1 levels (Kwon et al. 2005; Lotito and Frei 2006). In addition, dietary anthocyanins and hydroxycinnamic acids have been reported to reduce TNF- $\alpha$-induced up-regulation of various inflammatory mediators such as ICAM-1 or MCP-1. Therefore, the ability of polyphenols to mediate inflammatory processes is likely to contribute to their antiatherogenic properties.

The effect of flavonoids on the arterial wall due to their estrogenic activity is well known. Flavonoids reduce the risk of cardiovascular diseases (Kris-Etherton et al. 2002), decrease serum cholesterol, low-density lipoproteins (LDL) and triglyceride levels (Ricketts et al. 2005), prevent osteoporosis (Dang and Lowit 2005), and improve menopausal symptoms (McCann et al. 2005). Notably, work has already shown that the estrogenic properties of wine flavonoids including anthocyanins are due, in part, to their ability to bind the estrogen receptor (Chalopin et al. 2010; Schmitt and Stopper 2001).

In addition, flavonoids have been suggested to decrease cardiovascular risk by reducing levels of angiotensin II, a well-known proinflammatory mediator (Naruszewicz et al. 2007). It has already been reported that some anthocyanincontaining foods as well as delphinidin inhibit ACE activity (Actis-Goretta et al. 2006; Lacaille-Dubois et al. 2001; Persson et al. 2009).

Anthocyanins intake in humans has been estimated to be between 3 and $215 \mathrm{mg} /$ day (Chun et al. 2007; Frankel et al. 1995; Pérez-Jimenez et al. 2011; Wu et al. 2006). Most studies have shown very low bioavailability of anthocyanins based only on the measurement in plasma or urine of the original anthocyanins and their conjugated metabolites, glucuronidated, and sulfated anthocyanins (Manach et al. 2005). More recently, it has been established that the intestinal microflora plays a key role in the metabolism of anthocyanins. After ingestion, anthocyanins can be hydrolyzed by intestinal glucosidases and the resulting aglycones are further metabolised in the large intestine to other breakdown metabolites such as protocatechuic, gallic, syringic, and vanillic acids (Avila et al. 2009; Forester and Waterhouse 2008; Keppler and Humpf 2005; Vitaglione et al. 2007). Moreover, gallic acid has been determined in plasma after its ingestion at levels as high as $1.8 \mu \mathrm{mol} / \mathrm{L}$ in its original form and at $2.2 \mu \mathrm{mol} / \mathrm{L}$ as its derivative $4-O$ - methylgallic acid (Shahrzad and Bitsch 1998; Shahrzad et al. 2001). Therefore, metabolites produced by the intestinal microflora could account partly for the health benefits associated with anthocyanin consumption in humans.

The aim of this study was to further elucidate the potential mechanisms by which anthocyanins and their metabolites reduce the initial stages of atherosclerosis. Specifically, we have studied the effect of anthocyanins and their metabolites on (1) NO production and TNF- $\alpha$ secretion in macrophages, and (2) ICAM-1, VCAM-1, and MCP-1 secretion in endothelial cells. The ACE-inhibitory activity of anthocyanins and their metabolites was also measured. Finally, their ER $\alpha$ - and $\operatorname{ER} \beta$-binding ability was measured. Docking studies helped to rationalize selectivity on ERs.

\section{Materials and methods}

\section{Chemicals}

Cyanidin-3-O-glucoside, pelargonidin-3-O-glucoside, malvidin-3-O-glucoside, delphinidin-3-O-glucoside, and peonidin-3-O-glucoside were purchased from Extrasynthese (Lyon, France). Acetate buffer saline, neutral red, Griess reagent, crystal violet, LPS (lipopolysaccharide), human recombinant $\mathrm{TNF}-\alpha$, mouse recombinant $\mathrm{IFN}-\gamma, 17-\beta$ estradiol, PBS, Tween-20, BSA, ACE (peptidyl-dipeptidase A, EC 3.4.15.1), and the phenolic acids: gallic, syringic, protocatechuic, vanillic, sinapic, homogentisic, 4-hidroxybenzoic, phloroglucinol, 3-(2',5'-dimethoxybenzoil) propionic (DMB propionic), coumaric and caffeic acids were purchased from Sigma-Aldrich Química S.A. (Madrid, Spain). Ethanol 99\%, glacial acetic acid, and dimethyl sulfoxide (DMSO) were obtained from Panreac (Barcelona, Spain). Sodium dodecyl sulfate (SDS) was acquired from Fisher (Madrid, Spain). Dulbecco's modified Eagle's medium (DMEM), fetal bovine serum (FBS), penicillin/ streptomycin, trypsin, L-glutamine, and nonessential amino acids were purchased from Lonza (Barcelona, Spain). Estradiol $\left[2,4,6,7,16,17-{ }^{3} \mathrm{H}(\mathrm{N})\right]$ and scintillation counting liquid (Optifase HiSafe2) were obtained from Perkin-Elmer (Salem, MA, USA). Estrogen receptors $\alpha$ and $\beta$ (human recombinant produced in insect cells) were purchased from Invitrogen (Barcelona, Spain).

\section{Macrophages}

RAW 264.7 cells, a murine monocyte macrophage cell line, were maintained at $37^{\circ} \mathrm{C}$ in $5 \% \mathrm{CO}_{2}$ according to standard protocols (Rimbach et al. 2000). The medium consisted of DMEM with $4.5 \mathrm{~g} / \mathrm{L}$ glucose and L-glutamine 
supplemented with $10 \%$ FBS and $1 \%$ penicillin/streptomycin $(5,000 \mathrm{U} / \mathrm{mL})$. For experiments, cells were harvested with trypsin-EDTA and macrophages were plated in 24-well plates at a density of $5 \times 10^{4}$ in $0.5 \mathrm{~mL}$ of medium for the cytotoxicity test or in 6-well plates at a density of $2 \times 10^{5}$ in $2 \mathrm{~mL}$ of medium, for nitrite and TNF- $\alpha$ measurement. Finally, cells were cultured for $72 \mathrm{~h}$ until they reached $80 \%$ confluence. Cells in 6-well plates were treated with gallic, vanillic, protocatechuic, and syringic acids in a range of concentrations between 0.01 and $500 \mu \mathrm{M}$ or DMSO $(<0.1 \%)$ as follows; four different treatments were performed. (A) Cells were pre-treated for $3 \mathrm{~h}$ with the different compounds, washed twice with PBS, and then stimulated with $1 \mu \mathrm{g} / \mathrm{mL}$ LPS for $24 \mathrm{~h}$. (B) Cells were pretreated with the different compounds for $3 \mathrm{~h}$, washed twice with PBS, and then stimulated with $1 \mu \mathrm{g} / \mathrm{mL}$ LPS plus $1,000 \mathrm{U} / \mathrm{mL}$ IFN- $\gamma$ for $24 \mathrm{~h}$. (C) Cells were co-incubated with the different compounds at $200 \mu \mathrm{M}$ together with $1 \mu \mathrm{g} / \mathrm{mL}$ LPS for $24 \mathrm{~h}$. (D) Cells were co-incubated with the different compounds at $200 \mu \mathrm{M}$ and with $1 \mu \mathrm{g} / \mathrm{mL}$ LPS plus $1,000 \mathrm{U} / \mathrm{mL}$ IFN- $\gamma$ simultaneously for $24 \mathrm{~h}$. For all these experiments, control cells were grown under identical conditions but were not exposed to the test compound or LPS/IFN- $\gamma$. For the cytotoxic assay, cells were treated with all compounds at the maximal concentration used in the NO production assay.

\section{Endothelial cells}

EA.hy 926 cells, a cell line derived from human umbilical vein endothelial cells (HUVEC), were a generous gift from Prof. C.-J. S. Edgell, University of North Carolina at Chapel Hill. EA.hy 926 cells were generated by fusion of human umbilical vein endothelial cells (HUVEC) with the human lung carcinoma cell line A549 and have been extensively used as a cell model for endothelial function (Fuchs et al. 2005). Cells were grown in DMEM medium containing $4.5 \mathrm{~g} / \mathrm{L}$ glucose and L-glutamine and supplemented with $10 \%$ FBS and $1 \%$ penicillin/streptomycin $(5,000 \mathrm{U} / \mathrm{mL})$. Cells were harvested with trypsin-EDTA and seeded in $0.5 \mathrm{~mL}$ of medium in 24-well plates or $2 \mathrm{~mL}$ of medium in 6-well plates and cultured until they reached $80 \%$ confluence. After pre-treatment in 6-well plates with 10 and $100 \mu \mathrm{M}$ of gallic, vanillic, protocatechuic and syringic acids for $16 \mathrm{~h}$, cells were stimulated with $10 \mathrm{ng} /$ $\mathrm{mL}$ TNF- $\alpha$ for $6 \mathrm{~h}$.

Estrogen receptor (ER) competitive binding assay

The binding activity of anthocyanins and acids to human ER was determined using a radioactivity assay based on the ability of the different compounds to compete with
$3 \mathrm{H}$-labeled estradiol for the estrogen receptor. For the $\mathrm{ER} \beta$ - and ER $\alpha$-binding assay, the corresponding pure estrogen receptor was used at $2.4 \mathrm{nM}$ together with $5 \mathrm{nM}$ tritium-labeled estradiol ([2,4,6,7,16,17-3H] estradiol). Unlabeled estradiol, anthocyanins, and acids were prepared in DMSO $(<0.5 \%)$ and diluted in PBS-T (PBS + $0.15 \%$ Tween 20) including receptors and Estradiol- $\mathrm{H}^{3 *}$. Briefly, the same volume of each compound, Estradiol$\mathrm{H}^{3 *}$, and receptor were mixed in a final volume of $150 \mu \mathrm{L}$, thus the different compounds were tested at a concentration ranging from 1 to $200 \mu \mathrm{M}$. The mixture was incubated for $4 \mathrm{~h}$ at $23^{\circ} \mathrm{C}$ to allow receptor binding. Afterward, $50 \mu \mathrm{L}$ of charcoal (charcoal $0.1 \mathrm{~g} / \mathrm{mL}$ and BSA $0.02 \mathrm{~g} / \mathrm{mL}$ ) was added and the samples kept on ice for $15 \mathrm{~min}$ before being centrifuged at $6,000 \times g$ for $5 \mathrm{~min}$ to remove the non-bound Estradiol- $\mathrm{H}^{3 *}$. An aliquot of this supernatant $(150 \mu \mathrm{L})$ was added to $4 \mathrm{~mL}$ of scintillation counting liquid. The bound $[3 \mathrm{H}]$ estradiol was measured in a WinSpectral 1414 Liquid Scintillation Counter (Beckman, LS 6500). Three independent experiments containing three replicates were performed for each compound tested. Results are expressed as the percentage of specific binding of $[3 \mathrm{H}]$ estradiol to ER versus log of competitor concentration. $\mathrm{IC}_{50}$ values represent the concentration of test compound required to displace $50 \%[3 \mathrm{H}]$ estradiol from the receptor. $\mathrm{IC}_{50}$ values were determined by non-linear regression fitting of experimental data to a sigmoid equation.

\section{Docking studies}

Geometries of compounds $\mathrm{X}-\mathrm{Y}$ were first optimized using the ab initio quantum chemistry program Gaussian 03 (Frisch et al. 2004) and the B3LYP/3-21G* basis set. As macromolecules, the X-ray structures of estrogen receptor complexes with genistein were chosen (PDB codes: $1 \times 7 \mathrm{r}$ for $\mathrm{ER} \alpha$ and $1 \times 7 \mathrm{j}$ for $\mathrm{ER} \beta$ ). Crystallographic water molecule close to $\operatorname{Arg} 394$ (ER $\beta$ Arg346) and Glu353 (ER $\beta$ Glu305) were kept as they were considered to be part of the binding site. Different conformers of the ligands were docked using the Lamarckian genetic algorithm implemented in AutoDock 3.1 (Morris et al. 1998) by randomly changing the torsion angles and overall orientation of the molecule. A volume for exploration was defined in the shape of a three-dimensional grid $\left(80 \times 80 \times 90 \AA^{3}\right)$ with a spacing of $0.375 \AA$ that enclosed the binding site and included the residues that are known to be crucial for activity. At each grid point, the receptor's atomic affinity potentials for carbon, aromatic carbon, oxygen, nitrogen, sulfur, and hydrogen atoms were precalculated for rapid intra- and intermolecular energy evaluation of the docking solutions for each ligand. The original Lennard-Jonnes and 
hydrogen-bonding potentials provided by the program were used. The parameters for the docking using the LGA were identical for all docking jobs. After docking, the 100 solutions were clustered in groups with root mean square deviations less than $1.0 \AA$. The clusters were ranked by the lowest energy representative of each cluster.

\section{Cell viability}

The uptake of neutral red dye was used to assess cell viability as described previously (Valacchi et al. 2001). Macrophages and Ea.hy 926 cells were pre-treated in 24-well plates with the different test compounds for $24 \mathrm{~h}$. After incubation, the culture medium was removed and replaced with fresh medium containing $50 \mu \mathrm{g} / \mathrm{mL}$ of neutral red. Following incubation for $2 \mathrm{~h}$ at $37^{\circ} \mathrm{C}$, the medium was removed and the cells extracted using a solution comprising 50:49:1 (v/v/v) ethanol, water, and glacial acetic acid. Absorbance at $540 \mathrm{~nm}$ was recorded using a microplate reader (Power Wave XS, BIOTEK). For all cell culture experiments, compounds were dissolved in DMSO. The final DMSO concentration in the cell culture medium was $0.1 \%(\mathrm{v} / \mathrm{v})$ or less. Pre-treatment for RAW 264.7 macrophages with up to $500 \mu \mathrm{M}$ and treatment for Ea.hy 926 with up to $100 \mu \mathrm{M}$ of any of the assayed compounds did not affect cell viability.

\section{NO production}

NO production was assessed by the measurement of nitrite concentration $\left(\mathrm{NO}_{2}{ }^{-}\right)$in the medium using the Griess reaction (Wang and Mazza 2002b). Supernatants of cultured macrophages were collected and deproteinized with $0.3 \mathrm{M} \mathrm{NaOH}$ and $0.3 \mathrm{M} \mathrm{ZnSO}_{4}$. An equal volume of the Griess reagent (1\% sulfanilamide/0.1\% N-(1-naphthyl)ethylenediamine dihydrochloride/2.5\% $\left.\mathrm{H}_{3} \mathrm{PO}_{4}\right)$ and the deproteinized samples were incubated for $10 \mathrm{~min}$ at room temperature protected from light. The nitrite concentration was determined by measuring the absorbance at $548 \mathrm{~nm}$ against a standard curve for sodium nitrite (Park et al. 2000).

TNF- $\alpha$ secretion in RAW 264.7 macrophages

Supernatants from RAW 264.7 macrophages were collected for $\mathrm{TNF}-\alpha$ secretion measurements as described above for NO production measurements. Upon collection, samples were centrifuged at $15,700 \times g$ for $10 \mathrm{~min}$ and the supernatants kept at $-80^{\circ} \mathrm{C}$ until analysis. TNF- $\alpha$ secretion was measured using a commercially available enzymelinked immunosorbent assay (ELISA) kit (Mouse TNF- $\alpha$ immunoassay, eBioscence).
Secretion of monocyte chemoattractant protein 1 (MCP-1), intercellular adhesion molecule 1 (ICAM-1), and vascular cell adhesion molecule 1 (VCAM-1) by EA.hy 926 cells

Upon collection of the supernatant from Ea.hy 926 cells, samples were centrifuged at $15,700 \times g$ for $10 \mathrm{~min}$ and the supernatants were kept at $-80^{\circ} \mathrm{C}$ until analysis. The secretion of MCP-1, ICAM-1, and VCAM-1 by Ea.hy 926 cells was measured using commercially available ELISA kits (Diaclone, Bionova scientific).

\section{Determination of ACE-inhibitory activity}

ACE-inhibitory activity was measured by fluorescence using the method of Sentandreu and Toldrá (2006) with some modifications. Briefly, ACE (peptidyl-dipeptidase A, EC 3.4.15.1) working solution was diluted with $0.15 \mathrm{M}$ Tris buffer ( $\mathrm{pH}$ 8.3) containing $0.1 \mu \mathrm{M} \quad \mathrm{ZnCl}_{2}$ with $0.04 \mathrm{U} / \mathrm{mL}$ of enzyme in the final reaction solution. A total of $40 \mu \mathrm{L}$ of this working solution (or distilled water for the blank) was added to each microtiter plate well, with another $40 \mu \mathrm{L}$ of distilled water for the blank (B) or $40 \mu \mathrm{L}$ control (C) or $40 \mu \mathrm{L}$ samples $(\mathrm{S})$. The enzyme reaction was started by adding $160 \mu \mathrm{L}$ of $0.45 \mathrm{mM}$ o-Abz-Gly-pPhe $\left(\mathrm{NO}_{2}\right)$-Pro-OH (Bachem Feinchemikalien, Bubendorf, Switzerland) dissolved in $150 \mathrm{mM}$ Tris-base buffer ( $\mathrm{pH}$ 8.3), containing $1.125 \mathrm{M} \mathrm{NaCl}$, and the mixture was incubated at $37^{\circ} \mathrm{C}$. The fluorescence generated was measured at $30 \mathrm{~min}$ using a multiscan microplate fluorimeter (FLUOstar optima, BMG Labtech, Offeuburg, Germany). 96-well microplates (Porvair, Leatherhead, UK) were used. Excitation and emission wavelengths were 350 and $420 \mathrm{~nm}$, respectively. The software used to process the data was FLUOstar control (version 1.32 R2, BMG Labtech).

The ACE-inhibitory activity was evaluated in 11 phenolic acids: gallic, protocatechuic, syringic, vanillic, synapic, homogentisic, hydroxybenzoic, phloroglucinol, coumaric, caffeic, and DMB propionic acid and five anthocyanins: cyanidin-3-O-glucoside, malvidin-3-O-glucoside, delphinidin-3-O-glucoside, peonidin-3- $O$-glucoside, and pelargonidin-3-O-glucoside. All samples were diluted in distilled water or ethanol-water 30/70 (v/v).

The activity of each sample was tested in triplicate. Inhibitory activity was expressed as the concentration required to inhibit the original $\mathrm{ACE}$ activity by $50 \%\left(\mathrm{IC}_{50}\right)$. The formula applied to calculate the percentage of ACEinhibitory activity was: $100-(C-S) /(C-B)$, where $C$ is the fluorescence of ACE with o-Abz-Gly-p-Phe $\left(\mathrm{NO}_{2}\right)$ Pro-OH (fluorescence substrate) and without inhibitor, $S$ is the fluorescence of ACE with $o$-Abz-Gly- $p$-Phe $\left(\mathrm{NO}_{2}\right)$-Pro$\mathrm{OH}$ and with sample as inhibitor, and $\mathrm{B}$ is the fluorescence 
of the fluorescent substrate $o$-Abz-Gly-p-Phe $\left(\mathrm{NO}_{2}\right)$-Pro$\mathrm{OH}$. This parameter was plotted versus sample concentration and non-linear logarithmic adjustment was performed as indicated by Quirós et al. (2007) to estimate $\mathrm{IC}_{50}$.

\section{Statistical analysis}

The results were reported as means \pm standard deviation (SD) of at least three measurements or two in the case of ICAM-1, VCAM-1, and MCP-1, each performed in triplicate. One-way analysis of variance (ANOVA) was used to compare the means, and the least significant difference (LSD) test showed the values statistically different. Differences were considered significant at $P<0.05$. All statistical analyses were performed with Statgraphics Plus 5.1 (Statistical Graphics Corporation, Inc., Rockville, MD, USA).

\section{Results and discussion}

Effect of phenolic acids on NO production and TNF- $\alpha$ secretion in LPS and LPS/IFN- $\gamma$-stimulated macrophages

Untreated macrophages did not produce detectable amounts of NO after the 24-h incubation, but stimulation of macrophages with LPS increased NO production significantly $(62.9 \pm 20.2 \mathrm{NO} \mathrm{nmol} / \mathrm{mg}$ protein). A synergistic effect was observed when IFN- $\gamma$ was added simultaneously with LPS such that NO production was further increased $(100.1 \pm 9.0 \mathrm{nmol} / \mathrm{mg}$ protein). In the present study, gallic, vanillic, and syringic acids did not inhibit NO production in activated macrophages. Protocatechuic acid slightly but significantly inhibited NO production in a dose-dependent manner between 0 and $100 \mu \mathrm{M}$, reaching an inhibition higher than $25 \%$ at $100 \mu \mathrm{M}$ compared to LPS-treated control and by $13 \%$ at $100 \mu \mathrm{M}$ compared to LPS + IFN- $\gamma$-treated control (Table 1).

When we co-treated macrophages with protocatechuic acid $(10 \mu \mathrm{M})$ and LPS simultaneously, we found a $20 \%$ reduction in the NO content of the media despite observing no significant reduction when cells were pre-treated with $10 \mu \mathrm{M}$ protocatechuic acid $3 \mathrm{~h}$ prior to LPS stimulation. In addition, co-incubation of macrophages with $10 \mu \mathrm{M}$ protocatechuic acid together with LPS + IFN- $\gamma$, caused a larger inhibition of NO production (29\%) compared to pretreatment with $10 \mu \mathrm{M}$ protocatechuic acid before cytokine stimulation (Table 2). This enhanced inhibition of NO production seen with co-incubation compared to with pretreatment might be a result of a direct chemical interaction between the protocatechuic acid and the stimuli used.

Earlier studies have shown that the anti-inflammatory action of flavonoids is mediated via their inhibition of iNOS
Table 1 Effect of protocatechuic acid on the inhibition of nitric oxide production in RAW 264.7 macrophages

\begin{tabular}{llc}
\hline $\begin{array}{l}\text { Protocatechuic } \\
(\mu \mathrm{M})\end{array}$ & \multicolumn{2}{l}{ Inhibition of NO production $(\%)$} \\
\cline { 2 - 3 } & LPS 1 & $\begin{array}{l}\text { LPS } 1 \mu \mathrm{g} / \mathrm{mL}+\mathrm{IFN}-\gamma \\
1,000 \mathrm{U} / \mathrm{mL}\end{array}$ \\
\hline 25 & $\mu \mathrm{g} / \mathrm{mL}$ & $4.3 \pm 1.3^{*}$ \\
50 & $16.2 \pm 3.3^{*}$ & $6.1 \pm 0.3^{*}$ \\
100 & $21.3 \pm 3.4^{*}$ & $12.7 \pm 3.3^{*}$ \\
\hline
\end{tabular}

Cells were pre-treated with protocatechuic acid for $3 \mathrm{~h}$ and then stimulated for $24 \mathrm{~h}$ with LPS $(1 \mu \mathrm{g} / \mathrm{mL})$ or LPS $(1 \mu \mathrm{g} / \mathrm{mL})+$ INF- $\gamma$ $(1,000 \mathrm{U} / \mathrm{mL})$. Data were compared to activated controls treated with LPS $1 \mu \mathrm{g} / \mathrm{mL}(62.9 \pm 20.2 \mathrm{nmol} / \mathrm{mg}$ protein $)$ or LPS $1 \mu \mathrm{g} / \mathrm{mL}+$ IFN- $\gamma \quad 1,000 \mathrm{U} / \mathrm{mL}(101.1 \pm 9.0 \mathrm{nmol} / \mathrm{mg}$ protein $)$. Data derived from at least three independent experiments performed in triplicate and are expressed as means $\pm \mathrm{SD}$

* Statistical significance: $P<0.05$ comparing the value with control

Table 2 Effect of protocatechuic acid on nitric oxide inhibition in RAW 264.7 macrophages using two different experimental conditions

\begin{tabular}{lcc}
\hline $\begin{array}{l}\text { Protocatechuic } \\
(\mu \mathrm{M})\end{array}$ & \multicolumn{2}{l}{ Inhibition of NO production $(\%)$} \\
\cline { 2 - 3 } & LPS 1 & LPS $1 \mu \mathrm{g} / \mathrm{mL}+\mathrm{IFN}-\gamma$ \\
& $\mu \mathrm{g} / \mathrm{mL}$ & $1,000 \mathrm{U} / \mathrm{mL}$ \\
\hline Pre-treated & $2.4 \pm 16.9$ & $3.7 \pm 3.3$ \\
Co-treated & $19.7 \pm 7.5^{*}$ & $29.3 \pm 4.1^{*}$ \\
\hline
\end{tabular}

Cells pre-treated with $10 \mu \mathrm{M}$ protocatechuic acid for $3 \mathrm{~h}$ and then stimulated for $24 \mathrm{~h}$ with LPS $(1 \mu \mathrm{g} / \mathrm{mL})$ or LPS $(1 \mu \mathrm{g} / \mathrm{mL})+$ INF- $\gamma$ $(1,000 \mathrm{U} / \mathrm{mL})$ and cells co-incubated with protocatechuic acid and LPS $(1 \mu \mathrm{g} / \mathrm{mL})$ or LPS $(1 \mu \mathrm{g} / \mathrm{mL})+\operatorname{INF}-\gamma(1,000 \mathrm{U} / \mathrm{mL})$ for $24 \mathrm{~h}$. Data were compared to activated control. Experiments performed in triplicate, and data are expressed as means $\pm \mathrm{SD}$

* Statistical significance: $P<0.05$ comparing the value with control

protein and mRNA expression as well as their inhibition of nuclear factor $\mathrm{kB}$ (NF-kB) and STAT-1 activation, which are involved in the expression of several inflammatory genes (Chen et al. 2005; Hämäläinen et al. 1999).

We next assessed the effect of anthocyanin metabolites on TNF- $\alpha$ secretion. We found that exposure of macrophages to LPS led to TNF- $\alpha$ secretion $(3.0 \pm 0.1 \mathrm{ng}$ TNF$\alpha / \mathrm{mg}$ protein), and that exposure to both LPS and IFN $-\gamma$ together induced a synergistic effect on TNF- $\alpha$ secretion $(11.4 \pm 1.1 \mathrm{ng}$ TNF- $\alpha / \mathrm{mg}$ protein). Similar to the results obtained for NO production, we found that pre-treatment for LPS-stimulated cells with protocatechuic acid at concentrations higher than $10 \mu \mathrm{M}$ caused a reduction in TNF- $\alpha$ secretion, with a significant inhibition at $100 \mu \mathrm{M}$ protocatechuic acid of $39 \%$. For cells treated with LPS + IFN- $\gamma$ together, a low but significant inhibition of TNF- $\alpha$ secretion was observed only by protocatechuic acid at 50 and $100 \mu \mathrm{M}$ (11.1 and 21.5\%, respectively). Co-incubation with the other phenolic acids and stimulus did not affect TNF- $\alpha$ secretion. No effect on TNF- $\alpha$ was shown for any of 
the other polyphenols assayed, vanillic, protocatechuic, and syringic acids in our experimental conditions.

Monocyte-derived macrophages are the principal inflammatory cells in atheromas. Their activation is crucial to the progression of multiple inflammatory diseases such as septic shock, chronic inflammation, and atherosclerosis, via the release of inflammatory and cytotoxic mediators like cytokines or NO (Tamir and Tannenbaum 1996). In the present study, we have shown that exposing macrophages to LPS and IFN- $\gamma$ simultaneously induces a synergistic effect in terms of NO production as well as TNF- $\alpha$ secretion, in accordance with other authors (Orlicek et al. 1996).

Studies in the literature investigating the effects of anthocyanins on NO production and TNF- $\alpha$ secretion are controversial. García-Alonso et al. (2004) did not find an effect of anthocyanins on NO production or TNF- $\alpha$ secretion when used to pre-treat RAW 264.7 macrophages $24 \mathrm{~h}$ prior incubation with LPS. In contrast, Hämäläinen et al. (1999) observed an inhibition of NO production as well as of iNOS protein and mRNA expression with pelargonidin treatment for macrophages exposed to an inflammatory stimulus (LPS). Also, Wang and Mazza (2002a) demonstrated an inhibitory effect of anthocyanins on LPSinduced NO production in macrophages.

Recently, Long et al. (2010) have shown that some flavonoids may increase the levels of hydrogen peroxide in the cell culture medium, thereby possibly affecting also some of the parameters that have been measured within the present. This increase in $\mathrm{H}_{2} \mathrm{O}_{2}$ in response to the flavonoid treatment may be due to a rapid degradation of some flavonoids at neutral $\mathrm{pH}$ and $37^{\circ} \mathrm{C}$. This has been reported for anthocyanins such as delphinidin chloride, an extremely unstable compound, and may have also occurred in terms of its 3-glucoside (Avila et al. 2009). Furthermore, Long et al. (2010) demonstrated that different cell culture media may have different effects on $\mathrm{H}_{2} \mathrm{O}_{2}$ production for the same polyphenol test compound. Thus, compound instability and generation of $\mathrm{H}_{2} \mathrm{O}_{2}$ should be taken into account in interpreting effects of anthocyandins in cultured cells (Long et al. 2010).

Related to our findings, Yan et al. (2004) demonstrated that protocatechuic acid isopropyl ester reduced plasma TNF- $\alpha$, NO, and hepatic malondialdehyde levels in a mouse model of septic shock induced by LPS and D-galactosamine. In our study, protocatechuic acid exhibited a protective effect in LPS/INF- $\gamma$-induced macrophages by inhibiting the overproduction of inflammatory mediators, namely NO and TNF- $\alpha$.

In our work, and in accordance with other studies (Terra et al. 2007), we compared the ability of anthocyanin metabolites to inhibit NO production in macrophages using four different treatment protocols (pre-incubation with polyphenols and activation with LPS alone or LPS plus
INF- $\gamma$, and co-incubation with polyphenols and LPS alone or LPS plus INF- $\gamma$ ). When macrophages were co-incubated simultaneously with the test compound and stimulus, protocatechuic acid was found to exhibit the strongest inhibition of NO secretion. In this case, we propose that protocatechuic acid acts by scavenging NO radicals or by a direct interaction with LPS or IFN- $\gamma$. However, the high level of inhibition of NO production and TNF- $\alpha$ secretion observed in cells pre-incubated with protocatechuic acid before LPS activation may be due to different mechanisms of action of flavonoids, as described above.

It needs to be considered that the concentrations of protocatechuic acid, which inhibited NO secretion in our cell culture experiments, were very high and rather not in the physiological range. Protocatechuic acid has been detected in plasma (human and rat) at concentrations that are around $200 \mathrm{nmol} / \mathrm{L}$, which is 100 -fold higher than the original anthocyanins concentration in plasma (between 1 and $10 \mathrm{nmol} / \mathrm{L}$ ) (Caccetta et al. 2000) but still very much lower than the concentrations used in our cell culture experiments.

Our results suggest that foods rich in polyphenols, which may lead to elevated levels of protocatechuic acid in plasma, could be beneficial in the prevention of inflammatory diseases since they reduce the production of the cytotoxic oxidative stress mediator $\mathrm{NO}$ as well as the production of TNF- $\alpha$, a crucial cytokine for the synergistic induction of NO synthesis.

Effect of phenolic acids on MCP-1, ICAM-1, and VCAM-1 secretion in endothelial cells

Untreated EA.hy 926 cells released very low levels of MCP-1, ICAM-1, and VCAM-1 into the media. However, when treated with TNF- $\alpha(10 \mathrm{ng} / \mathrm{mL})$ to mimic proinflammatory conditions, there was a marked increase in the secretion of MCP-1 (2.2 ng/mL \pm 0.3$)$, ICAM-1 $(0.9 \mathrm{ng} /$ $\mathrm{mL} \pm 0.1)$, and VCAM-1 (4.9 ng/mL \pm 3.6$)$. Pre-treatment with gallic acid elicited a statistically significant dosedependent decrease in the secretion of MCP-1, ICAM-1, and VCAM-1 at concentrations $\geq 10 \mu \mathrm{M}$ compared with activated control cells (Table 3). None of the other polyphenols assayed, vanillic, protocatechuic, and syringic acids, showed any effect on the secreted levels of MCP-1, ICAM-1, and VCAM-1 in our experimental conditions.

Many epidemiological studies have reported that moderate wine consumption exerts a protective effect against cardiovascular diseases (Estruch 2000; Gronbaek et al. 2000). In addition, clinical studies have demonstrated that daily intake of wine reduces monocyte adhesion and circulating markers of inflammation (Badia et al. 2004; Estruch et al. 2004). Moreover, Sacanella et al. (2007) showed a more potent effect of red wine versus white wine, possibly 
Table 3 Effect of gallic acid on MCP-1, ICAM-1, and VCAM-1 secretion in Ea.hy 926

\begin{tabular}{llll}
\hline Gallic acid $(\mu \mathrm{M})$ & MCP-1 $(\%)$ & ICAM-1 $(\%)$ & VCAM-1 $(\%)$ \\
\hline 0 & 100 & 100 & 100 \\
1 & $96.2 \pm 5.0$ & $94.5 \pm 4.4$ & $88.0 \pm 38.3$ \\
10 & $85.7 \pm 3.1^{*}$ & $91.9 \pm 0.6^{*}$ & $76.2 \pm 13.7^{*}$ \\
50 & $81.2 \pm 2.4^{*}$ & $88.6 \pm 5.6$ & $50.8 \pm 5.9^{*}$ \\
100 & $78.9 \pm 1.8^{*}$ & $79.9 \pm 0.6^{*}$ & $41.2 \pm 4.9^{*}$ \\
\hline
\end{tabular}

Cells were pre-treated with gallic acid $(0,1,10,50$, and $100 \mu \mathrm{M})$ for $16 \mathrm{~h}$ and then activated $6 \mathrm{~h}$ with TNF- $\alpha(10 \mathrm{ng} / \mathrm{mL})$. Data were compared to TNF- $\alpha$-stimulated controls (not treated with gallic acid). Data were derive from three independent experiments performed in duplicated and are expressed as means \pm SD

* Statistical significance: $P<0.05$ comparing the value with control due to its higher anthocyanin content. A suppression of NF$\mathrm{kB}$ in white blood cells by red wine was suggested to play a key role in its anti-inflammatory effects (Blanco-Colio et al. 2000). In accordance with these studies, we observed a significant reduction in MCP-1, ICAM-1, and VCAM-1 levels when endothelial cells were pre-treated with gallic acid. This reduction was especially marked in the case of VCAM-1. Previous studies have reported that endothelial cells in human atherosclerotic lesions increase cell adhesion molecules (CAMs) and MCP-1. Therefore, gallic acid might be an effective protector against monocyte recruitment in inflammatory vessels and may prove useful in the prevention of atherosclerotic lesion development due, in part, to a decrease in MCP-1, which promotes monocytes infiltration into the arterial wall.

\section{Determination of ACE-inhibitory activity}

We assessed the ACE-inhibitory activity of the potentially bioactive phenolic acids and anthocyanins by measuring their $\mathrm{IC}_{50}$ values (the concentration required to inhibit the original ACE activity by $50 \%$ ). The ACE-inhibitory activity was first determined for all the test compounds at a concentration of $500 \mu \mathrm{M}$, and only those ones showing a percentage of inhibition higher than 50\% where used to calculate their corresponding $\mathrm{IC}_{50}$ vaules. The ACE-inhibitory activity was then tested at 6 different concentrations between 1 and $500 \mu \mathrm{M}$ in order to obtain a dose-response curve. Data are summarized in Table 4. The anthocyanins inhibited ACE activity in a dose-dependent manner, with delphinidin-3-glucoside being the most active $\left(\mathrm{IC}_{50}=\right.$ $65.4 \mu \mathrm{M})$ followed closely by cyanidin-3-O-glucoside $\left(\mathrm{IC}_{50}=70.8 \mu \mathrm{M}\right)$, pelargonidin-3- $O$-glucoside $\left(\mathrm{IC}_{50}=\right.$ $77.7 \mu \mathrm{M})$, malvidin-3- $O$-glucoside $\left(\mathrm{IC}_{50}=83.9 \mu \mathrm{M}\right)$, and peonidin-3-O-glucoside $\left(\mathrm{IC}_{50}=104.6 \mu \mathrm{M}\right)$. This observation suggests that the presence of a hydroxyl group, as well as the O-glycosides structure, enhances the inhibitory activity. We found that of all of the phenolic acids, only
Table 4 ACE-inhibitory activity of anthocyanins and phenolic acids

\begin{tabular}{ll}
\hline Sample & $\mathrm{IC}_{50}(\mu \mathrm{M})$ \\
\hline Gallic acid & $332.4 \pm 40.1$ \\
Caffeic acid & $157.3 \pm 16.1$ \\
Coumaric acid & $504.2 \pm 31.5$ \\
Malvidin-3- $O$-glucoside & $83.9 \pm 5.1$ \\
Delphinidin-3- $O$-glucoside & $65.4 \pm 4.0$ \\
Cyanidin-3- $O$-glucoside & $70.8 \pm 2.0$ \\
Pelargonidin-3- $O$-glucoside & $77.7 \pm 2.3$ \\
Peonidin-3- $O$-glucoside & $104.6 \pm 5.8$ \\
\hline
\end{tabular}

$\mathrm{IC}_{50}$ : concentration of compound needed to inhibit the original ACE activity by $50 \%$

caffeic, gallic, and coumaric acids exhibited a marginal ACE-inhibitory activity with $\mathrm{IC}_{50}$ values of $157.3,332.4$, and $504.2 \mu \mathrm{M}$, respectively. All the other assayed compounds, protocatechuic, syringic, vanillic, synapic, homogentisic, hydroxybenzoic, phloroglucinol, and DMB propionic acid showed an inhibition of ACE lower than $50 \%$ for a $500 \mu \mathrm{M}$ concentration.

The in vitro ACE-inhibitory activity of flavonoids is due to the generation of chelate complexes with the zinc atom within the active center of ACE (García-Saura et al. 2005). Free hydroxyl groups of phenolic compounds are suggested to be important structural moieties to chelate the zinc ions, thus inactivating the ACE activity. It may therefore be the hydroxyl groups within the anthocyanins and phenolics acids that are responsible for their ACE-inhibitory activity. In fact, ACE-inhibitory activity has been already demonstrated in some compounds derived from plants such as flavonoids (Wille et al. 2001), terpenoids (Morigiwa et al. 1986), peptides (Kinoshita et al. 1993), and procyanidins (Wagner and Elbl 1992).

It is therefore likely that anthocyanins and their breakdown metabolites, phenolic acids, have hypotensive and protective effects on endothelial function due, at least in part, to their ACE-inhibitory effect since angiotensin II regulates arterial blood pressure, adhesion molecule expression, cytokines, chemokines, and growth factors within the arterial wall.

\section{Relative affinity for $\mathrm{ER} \alpha$ and $\mathrm{ER} \beta$}

The first step to determine the estrogenic activity of a given compound is to measure the binding of this potential ligand to the estrogenic receptor. In general, the affinity of flavonoids to bind to $\mathrm{ER} \alpha$ and $\beta$ is lower than that of $17-\beta$ estradiol. However, some studies have confirmed that genistein, daidzein, and equol have a good affinity for ER, especially for $\operatorname{ER} \beta$ (Mueller et al. 2004).

The ER-binding affinity of anthocyanins and their metabolites was determined in a radioactivity assay by 
Table 5 Relative affinity of anthocyanins and phenolic acids for ER $\alpha$ and $\mathrm{ER} \beta$

\begin{tabular}{lll}
\hline Compound & $\mathrm{ER} \alpha \mathrm{IC}_{50}(\mu \mathrm{M})^{*}$ & $\mathrm{ER} \beta \mathrm{IC}_{50}(\mu \mathrm{M})^{*}$ \\
\hline Delphinidin-3-O-glucoside & $\mathrm{NA}$ & $63.2 \pm 0.8$ \\
Pelargonidin-3- $O$-glucoside & $61.3 \pm 0.7$ & $93.0 \pm 0.8$ \\
Peonidin-3- $O$-glucoside & $64.4 \pm 0.9$ & $\mathrm{NA}$ \\
Malvidin-3- $O$-glucoside & $\mathrm{NA}$ & $\mathrm{NA}$ \\
Cyanidin-3-O-glucoside & $\mathrm{NA}$ & $\mathrm{NA}$ \\
Gallic acid & $\mathrm{NA}$ & $100.3 \pm 0.9$ \\
Protocatechuic acid & $\mathrm{NA}$ & $\mathrm{NA}$ \\
Syringic acid & $\mathrm{NA}$ & $\mathrm{NA}$ \\
Vanillic acid & $\mathrm{NA}$ & $\mathrm{NA}$
\end{tabular}

* $\mathrm{IC}_{50}$ is defined as the concentration required to achieve $50 \%$ inhibition in the binding of $\left[{ }^{3} \mathrm{H}\right]$-estradiol to the corresponding estrogen receptor (ER). NA not achieve binding at the assayed concentration. $\mathrm{IC}_{50}$ values are shown as mean $\pm \mathrm{SD}$

measuring their ability to compete with $17-\beta$-estradiol for the ER. Table 5 summarizes the $\mathrm{IC}_{50}$ values obtained (concentration required to inhibit binding of $\left[{ }^{3} \mathrm{H}\right]$-estradiol to the corresponding ER by 50\%). Pelargonidin-3-glucoside showed affinity for both receptors, with a relatively higher affinity for $\operatorname{ER} \alpha(61.3 \mu \mathrm{M} \pm 0.7)$ than for $\operatorname{ER} \beta$ (93.0 $\mu \mathrm{M} \pm 0.8)$, whereas peonidin-3-glucoside only demonstrated affinity for $\mathrm{ER} \alpha(64.4 \mu \mathrm{M} \pm 0.9)$ and delphinidin-3-glucoside only reasonable affinity for ER $\beta$ $(63.2 \mu \mathrm{M} \pm 0.8)$.

Among the phenolic acid metabolites assayed, gallic acid showed affinity for ERß (100.3 $\mu \mathrm{M} \pm 0.9)$ but did not show affinity for $\mathrm{ER} \alpha$.

It is interesting to note that delphinidin-3-glucoside and gallic acid, with similar structural features in the hydroxylation pattern of their B-ring, showed affinity for $\operatorname{ER} \beta$, but not for ER $\alpha$. Moreover, delphinidin-3-glucoside demonstrated a binding affinity for $\operatorname{ER} \beta$ that is approximately twofold higher than that of gallic acid. These results are in accordance with those obtained in the molecular modeling studies and could be explained by the hypotheses that two molecules of gallic acid are able to bind to the ER and display estrogenic/anti-estrogenic activities.

All other test compounds did not show any affinity for the ER at the concentrations tested.

Schmitt and Stopper (2001) have reported that anthocyanidins (the aglycones of anthocyanins) have high affinity toward ER $\alpha$. They showed that pelargonidin $(6.8 \mu \mathrm{M})$ had the highest affinity among the assayed anthocyanidins followed by delphinidin $(10.4 \mu \mathrm{M})$ and cyanidin $(12.2 \mu \mathrm{M})$ (Cornwell et al. 2004). In a similar way, Chalopin et al. (2010) showed that the endothelium-dependent vasorelaxation of delphinidin and a red wine extract is mediated via $\mathrm{ER} \alpha$. With respect to $\mathrm{ER} \alpha$, the presence of up to 2-OH groups in the B-ring of the molecular structure decreased the affinity of the anthocyanins to the ER $\alpha$ (Fang et al. 2001). In contrast, delphinidin-3-glucoside and gallic acid with 3-OH groups demonstrated the highest affinity for $\mathrm{ER} \beta$ in our study.

Study of the binding mode on $\operatorname{ER} \beta$ and $\operatorname{ER} \alpha$ : docking studies

We carried out docking studies for the anthocyanidins listed in Table 5 (delphinidin, pelargonidin, peonidina, malvidin, and cyanidin) and their metabolites (gallic and protocatechuic acids; see Fig. 1 for chemical structures) in the ligand-binding domains (LBD) of both $\mathrm{ER} \alpha$ and $\mathrm{ER} \beta$. In general, docking predictions were in agreement with affinity data.

Taking genistein (binding mode) as a reference, our purpose was to study whether the docking protocol was able to predict both the binding poses for anthocyanidins and any binding preference that could suggest selectivity. Regarding the binding poses, the most favorable poses corresponded to docked orientations where hydrogen bonds between hydroxyl groups and His524 (ER $\beta$ His475) and Arg394-Glu353 (ER $\beta$ Arg346-Glu305) are the main interactions, anchoring the ligand within the LBD of ER.
Fig. 1 Chemical structure of the main anthocyanidins and the phenolic metabolites assayed<smiles></smiles><smiles></smiles><smiles></smiles><smiles></smiles><smiles></smiles><smiles>O=C(O)c1cc(O)c(O)c(O)c1</smiles><smiles>O=C(O)c1ccc(O)c(O)c1</smiles> 


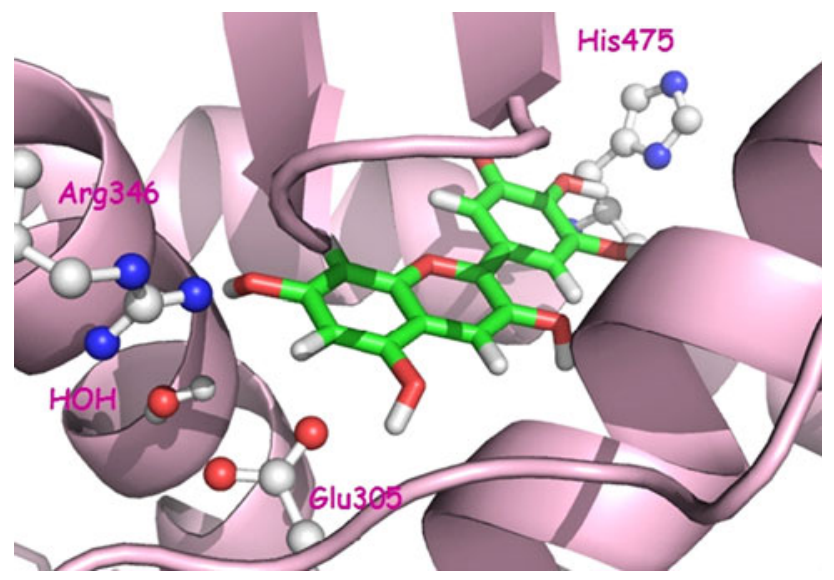

Fig. 2 ER $\beta$ residues, highlighted alongside docked delphinidin, viewed from the front of the binding pocket

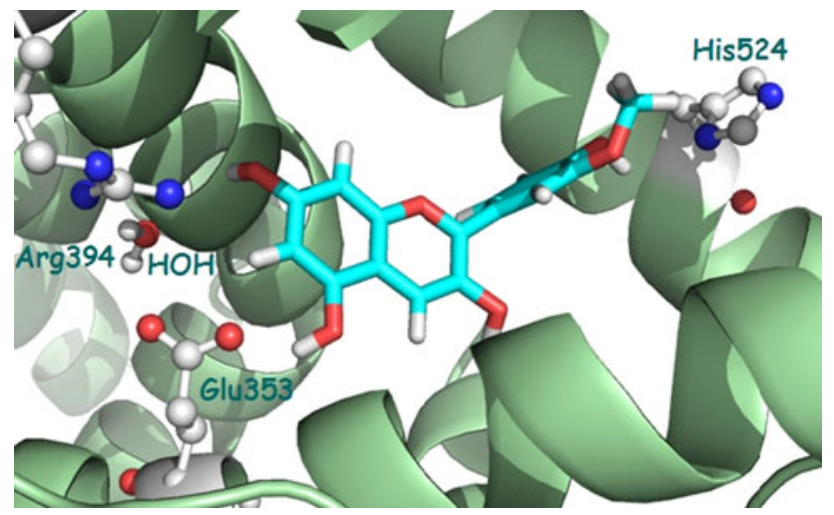

Fig. 3 Docking pose obtained for peonidin inside ER $\alpha$-binding site. $\mathrm{ER} \alpha$ residues in the ligand binding domain are highlighted

These interactions are crucial to give rise to a stable ligandreceptor complex that could account for the observed affinity. Regarding selectivity, no solutions were predicted for delphinidin by AutoDock when docked to $\mathrm{ER} \alpha$, while favorable binding orientations were found in $\operatorname{ER} \beta$ (Fig. 2). On the contrary, in the case of peonidin, only favorable poses were located in ER $\alpha$ (Fig. 3). These results are in agreement with the experimental affinity values (Table 5), which show $\mathrm{ER} \beta$ selectivity for delphinidin and $\mathrm{ER} \alpha$ selectivity for peonidin. Our results are also in agreement with previous reports (Schmitt and Stopper 2001). As mentioned above, it should be pointed out that delphinidin has 3-OH groups in the B-ring. However, for pelargonidin, similar binding results were predicted without meaningful differences. Also, affinity assays only exhibited a slight preference toward $\mathrm{ER} \alpha$.

No binding poses were found for malvidin and cyanidin, in agreement with the absence of affinity, suggesting that these compounds are not suitable ER ligands.

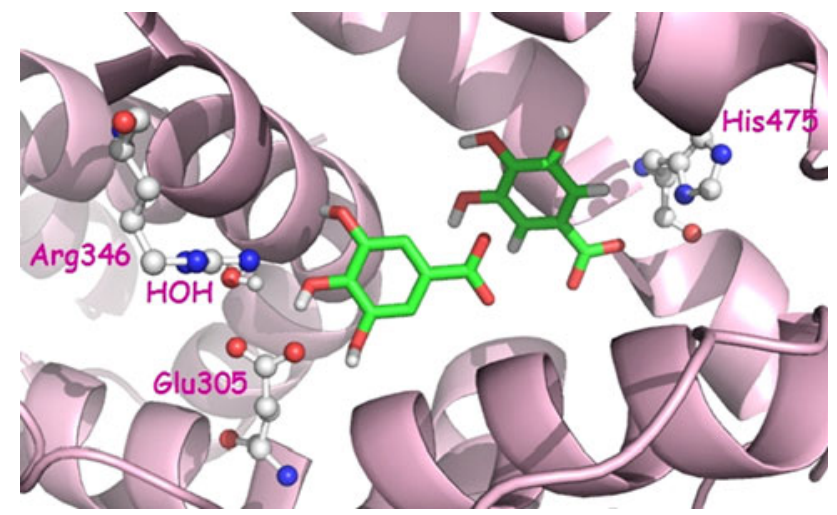

Fig. 4 Model of two docked molecules of gallic acid inside the ER $\beta$ ligand-binding domain: hydrogen bonds between hydroxyl groups and His475 and Arg346-Glu305 are shown

In the case of phenolic acids, which are smaller molecules, all showed ability to bind to different regions of the LBD. Our computational efforts were then directed toward the study of the putative binding of two molecules within the LBD. AutoDock predicted that two units of both phenolic acids are able to interact simultaneously with the LBD, by adopting several orientations. Thus, we found that this hypothesis was possible from a theoretical perspective, since binding poses were found to reproduce the main interactions present in large ligands, justifying the antiproliferative effect shown in the MCF-7 cell model: hydrogen bonds between hydroxyl groups and His524 (ER $\beta$ His475) and Arg394-Glu353 (ER $\beta$ Arg346-Glu305) (Fig. 4). From the study of interactions and predicted binding energies, it can be concluded that gallic acid binds with higher affinity to both ERs, compared with protocatechuic acid. Regarding selectivity, similar binding energy values were predicted for both $\mathrm{ER} \alpha / \mathrm{ER} \beta$ receptors. With these theoretical results, selectivity cannot be sighted.

Our results suggest that gallic acid could potentially be considered as an enterophytoestrogen; a gut microfloraderived metabolite that can exhibit higher estrogenic/antiestrogenic activity than its corresponding precursor.

Nevertheless, the fact that these polyphenols demonstrate affinity for the estrogen receptors and display agonist/ antagonist effects may suggest that these compounds could act in target genes and in tissues where they could collaborate in the health-promoting properties of anthocyanins.

\section{Concluding remark}

The mechanisms underlying the antiatherogenic effect of anthocyanins consumption is probably multifactorial. Our study suggests that the protective health effects of anthocyanins might not only be due to anthocyanins themselves, 
but also to their metabolites produced by the action of the gut microflora. Both anthocyanins and their phenolic acid metabolites might play a role in decreasing vascular inflammatory markers, such as cytokines and adhesion and chemoattractant molecules. Despite observing a slight modulation of NO production by protocatechuic acid, the concentrations required to produce this effect do not fit with this being a potential mechanism of action for the antiatherogenic properties of anthocyanins. It might be the ability of anthocyanins and three of their metabolites to inhibit ACE activity, which could decrease the expression of inflammatory markers and therefore improve endothelial function. On the other hand, some of the assayed metabolites have shown a relatively important affinity for ER $\alpha$ and $\beta$, which regulate transcription of target genes, such as NF-kB. This affinity could also be implicated in atheromatosis. Overall, the concentrations of anthocyanins and their metabolites, as used in the present cell culture and in vitro assays mediating anti-inflammatory, anti-adhesive, anti-estrogenic, and angiotensin-converting enzyme inhibitory activities were often manifold higher than those physiologically achievable (Vitaglione et al. 2007). Further research, preferably in vivo, is necessary to determine whether, and to what extent, anthocyanin metabolites play a role in the prevention of atherosclerosis in humans.

Acknowledgments This work was supported by the Spanish Ministry of Science and Innovation through projects AGL2006-05453, AGL2008-01713, AGL2009-07894, SAF2008-00945, and the Consolider-Ingenio 2010 Programme (FUN-C-FOOD, CSD2007-00063). M. Hidalgo wishes to thank CSIC, for a JAE predoctoral fellowship (JAEPre094).

\section{References}

Actis-Goretta L, Ottaviani JI, Fraga CG (2006) Inhibition of angiotensin converting enzyme activity by flavanol-rich foods. J Agric Food Chem 54:229-234

Avila M, Hidalgo M, Sánchez-Moreno C, Pelaez C, Requena T, de Pascual-Teresa S (2009) Bioconversion of anthocyanin glycosides by Bifidobacteria and Lactobacillus. Food Res Int 42:1453-1461

Badia E, Sacanella E, Fernandez-Solá J, Nicolás JM et al (2004) Decreased tumor necrosis factor-induced adhesion of human monocytes to endothelial cell after moderate alcohol consumption. Am J Clin Nutr 80:225-230

Blanco-Colio LM, Valderrama M, Alvarez-Sala LA, Bustos C et al (2000) Red wine intake prevents nuclear factor-kB activation in peripheral blood mononuclear cells of healthy volunteers during postprandial lipemia. Circulation 102:1020-1026

Caccetta RA, Croft KD, Beilin LJ, Puddey IB (2000) Ingestion of red wine significantly increases plasma phenolic acid concentrations but does not acutely affect ex vivo lipoprotein oxidizability. Am J Clin Nutr 71:67-74

Cassidy A, de Pascual-Teresa S, Rimbach G (2003) Molecular mechanisms by which dietary isoflavones potentially prevent atherosclerosis. Expert Rev Mol 30:1-15
Chalopin M, Tesse A, Martínez MC, Rognan D, Arnal JF, Andriantsitohaina R (2010) Estrogen receptor alpha as a key target of red wine polyphenols action on the endothelium. PLoS One 5:e8554

Chen JC, Ho FM, Chao P-DL, Chen C-P et al (2005) Inhibition of iNOS gene expression by quercetin is mediated by the inhibition of $\mathrm{I} \kappa \mathrm{B}$ kinase, nuclear factor $-\kappa \mathrm{B}$ and STAT1, and depends on heme oxygenase-1 induction in mouse BV-2 microglia. Eur $\mathrm{J}$ Pharmacol 521:9-20

Chun OK, Chung SJ, Song WO (2007) Estimated dietary flavonoid intake and major food sources of U.S. adults. J Nutr 37:12441252

Cornwell T, Cohick W, Raskin I (2004) Dietary phytoestrogen and health. Rev Phytochem 65:995-1016

Dang ZC, Lowit C (2005) Dose-dependent effects of phytoestrogens on bone. Trends Endocrinol Metab 16:207-213

Estruch R (2000) Wine and cardiovascular disease. Food Res Int 33:219-226

Estruch R, Sacanella E, Badia E, Antúnez E et al (2004) Different effects of red wine and gin consumption on inflammatory biomarkers of atherosclerosis: a pro-spective randomized crossover trial. Effects of wine on inflammatory markers. Atherosclerosis 175:117-123

Fang H, Tong W, Leming MS, Blair R et al (2001) Structure-activity relationships for large diverse set of natural, synthetic, and environmental estrogens. Chem Res Toxicol 14:280-294

Forester SC, Waterhouse AL (2008) Identification of Cabernet Sauvignon anthocyanin gut microflora metabolites. J Agric Food Chem 56:9299-9304

Frankel EN, Waterhouse AL, Teissedre PL (1995) Principal phenolic phytochemicals in selected California wines and their antioxidant activity in inhibiting oxidation of human low-density lipoproteins. J Agric Food Chem 43:890-894

Frisch MJ, Trucks GW, Schlegel HB, Scuseria GE et al (2004) Gaussian 03, revision C.02. Gaussian Inc., Wallingford

Fuchs D, Erhard P, Turner R, Rimbach G, Daniel H, Wenzel U (2005) Genistein reverses changes of the proteome induced by oxidizedLDL in EA.hy 926 human endothelial cells. J Proteome Res 4:369-376

García-Alonso M, Rimbach G, Rivas-Gonzalo JC, de Pascual-Teresa S (2004) Antioxidant and cellular activity of anthocyanidins and their corresponding vitisins A-studies in platelets, monocytes and human endothelial cells. J Agric Food Chem 52:3378-3384

García-Alonso M, Minihane AM, Rimbach G, Rivas-Gonzalo JC, de Pascual-Teresa S (2009) Red wine anthocyanins are rapidly absorbed in humans and affect monocyte chemoattractant protein 1 levels and antioxidant capacity of plasma. J Nutr Biochem 20:521-529

García-Saura MF, Galisteo M, Villar IC, Bermejo A et al (2005) Effects of chronic quercetin treatment in experimental renovascular hypertension. Mol Cell Biochem 270:147-155

González-Gallego J, García-Mediavilla MV, Sánchez-Campos S, Tuñón MJ (2010) Fruit polyphenols, immunity and inflammation. Br J Nutr 104:S15-S27

Gray JI, DeWitt DL (1999) Antioxidant and antiinflammatory activities of anthocyanins and their aglycon, cyaniding, from tart cherries. J Nat Prod 62:294-296

Gronbaek M, Becker U, Johansen D, Gottschau A et al (2000) Type of alcohol consumed and mortality from all causes, coronary heart disease and cancer. Ann Intern Med 133:411-419

Hämäläinen $\mathrm{M}$, Nieminen R, Vuorela $\mathrm{P}$, Heinonen $\mathrm{M}$, Moilanen E (1999) Anti-Inflammatory effects of flavonoids: genistein, kaempferol, quercetin, and daidzein inhibit STAT-1 and NF$\kappa \mathrm{B}$ activations, whereas flavone, isorhamnetin, naringenin, and pelargonidin inhibit only NF- $\kappa \mathrm{B}$ activation along with their inhibitory effect on iNOS expression and NO production in activated macrophages. Med Inflamm 2007:1-10 
Kahkonen MP, Heinonen M (2003) Antioxidant activity of anthocyanins and their aglycons. J Agric Food Chem 51:628-633

Keppler K, Humpf HU (2005) Metabolism of anthocyanis and their phenolic degradation products by the intestinal microflora. Bioorg Med Chem 13:5195-5205

Kinoshita E, Yamakoshi J, Kikuchi M (1993) Purification and identification of an angiotensin converting enzyme from soy sauce. Biosci Biotechno Biochem 57:1107-1110

Kris-Etherton PM, Hecker KD, Bonanome A, Coval SM et al (2002) Bioactive compounds in foods: their role in the prevention of cardiovascular disease and cancer. Am J Med 113:71S-88S

Kwon HM, Choi YJ, Jeong YJ, Kang SW et al (2005) Antiinflammatory inhibition of endothelial cell adhesion molecule expression by flavone derivatives. J Agric Food Chem 53:51505157

Lacaille-Dubois MA, Franck U, Wagner H (2001) Search for potential angiotensin converting enzyme (ACE)-inhibitors from plants. Phytomedicine 8:47-52

Landberg R, Sun Q, Rimm EB, Cassidy A et al (2011) Selected dietary flavonoids are associated with markers of inflammation and endothelial dysfunction in U.S. women ${ }^{1,2}$. J Nutr $141: 618-625$

Long LH, Hoi A, Halliwell B (2010) Instability of, and generation of hydrogen peroxide by, phenolic compounds in cell culture media. Arch Biochem Biophys 501:162-169

Lotito SB, Frei BD (2006) Dietary flavonoids attenuate tumor necrosis factor $\alpha$-induced adhesion molecule expression in human aortic endothelial cells. J Biol Chem 281:37102-37110

Manach C, Williamson G, Morand C, Scalbert A, Remesy C (2005) Bioavailability and bioefficacy of polyphenols in humans. I. Review of 97 bioavailability studies. Am J Clin Nutr 81:230-242

Matsumoto H, Nakamura Y, Hirayama M, Yoshiki Y, Okubo K (2002) Antioxidant activity of black currant anthocyanin aglycons and their glycosides measured by chemiluminescence in a neutral $\mathrm{pH}$ region and in human plasma. J Agric Food Chem 50:5034-5037

McCann MJ, Gill CI, McGlynn H, Rowland IR (2005) Role of the mammalian lignans in the prevention and treatment of prostate cancer. Nutr Cancer 52:1-14

Morigiwa A, Kitabatake K, Fujimoto Y, Ikekawa N (1986) Angiotensin converting enzyme inhibitory triterpenes from Ganoderma lucidum. Chem Pharm Bull 34:3025-3028

Morris GM, Goodsell DS, Halliday RS, Huey R et al (1998) Automated docking using a Lamarckian genetic algorithm and empirical binding free energy function. J Comput Chem 19:1639-1662

Mueller SO, Simon S, Chae K, Metzler M, Korach KS (2004) Phytoestrogens and their human metabolites show distinct agonistic and antagonistic properties on estrogen receptor $\alpha$ $(\mathrm{ER} \alpha)$ and $\mathrm{ER} \beta$ in human cells. Toxicol Sci 80:14-25

Naruszewicz M, Laniewska I, Millo B, Dluzniewski M (2007) Combination therapy of statin with flavonoids rich extract from chokeberry fruits enhanced reduction in cardiovascular risk markers in patients after myocardial infraction (MI). Atherosclerosis 194:179-184

Orlicek SL, Meals E, English BK (1996) Differential effects of tyrosine kinase inhibitors on tumor necrosis factor and nitric oxide production by murine macrophages. J Infect Dis 174:638-642

Park YC, Rimbach G, Saliou C, Valacchi G, Packer L (2000) Activity of monomeric, dimeric, and trimeric flavonoids on NO production, TNF-alpha secretion, and NF-kappa B-dependent gene expression in RAW 264.7 macrophages. FEBS Lett 465:93-97

Pérez-Jimenez J, Fezeu L, Touvier M, Amault N et al (2011) Dietary intake of 337 polyphenols in French adults. Am J Clin Nutr 93:1-9
Persson IA, Persson K, Andersson RG (2009) Effect of Vaccinium myrtillus and its polyphenols on angiotensin-converting enzyme activity in human endothelial cells. J Agric Food Chem 57:4626-4629

Quirós A, Ramos M, Muguerza B, Delgado MA et al (2007) Identification of novel antihypertensive peptides in milk fermented with Enterococcus faecalis. Int Dairy J 17:33-41

Ricketts M-L, Moore DD, Banz WJ, Mezei O, Shay NF (2005) Molecular mechanism of action of the soy isoflavonas includes activation of promiscuous nuclear receptor. Rev J Nutr Biochem 16:321-330

Rimbach G, Valacchi G, Canali R, Virgili F (2000) Macrophages stimulated with INF-gamma activate NF-KappaB and induce MCP-1 gene expression in primary human endothelial cells. Mol Cell Biol Res Commun 3:238-242

Rotelli AE, Guardia T, Juárez AO, de la Rocha NE, Pelzer LE (2003) Comparative study of flavonoids in experimental models of inflammation. Pharmacol Res 48:601-606

Sacanella E, Vázquez-Agell M, Mena MP, Antúnez E et al (2007) Down-regulation of adhesion molecules and other inflammatory biomarkers after moderate wine consumption in healthy women: a randomized trial. Am J Clin Nutr 86:1463-1469

Schmitt E, Stopper H (2001) Estrogenic activity of naturally occurring anthocyanidins. Nutr Cancer 41:145-149

Sentandreu MA, Toldrá F (2006) A rapid, simple and sensitive fluorescence method for the assay of angiotensin-I converting enzyme. Food Chem 97:546-554

Shahrzad S, Bitsch I (1998) Pharmacokinetics of gallic acid and its relative bioavailability from tea in healthy humans. J Chromatogr B Biomed Sci 705:87-95

Shahrzad S, Aoyagi K, Winter A, Koyama A, Bitsch I (2001) Pharmacokinetics of gallic acid and its relative bioavailability from tea in healthy humans. J Nutr 131:1207-1210

Tamir S, Tannenbaum SR (1996) The role of nitric oxide (NO) in the carcinogenic process. Biochim Biophys Acta 1288:F31-F36

Terra X, Valls J, Vitrac X et al (2007) Grape-seed procyanidins act as antiinflammatory agents in endotoxin-stimulated RAW 264.7 Macrophages by inhibiting NFkB signaling pathway. J Agric Food Chem 55:4357-4365

Tsuda T, Watanabe M, Ohshima K, Norinobu S et al (1994) Antioxidative activity of the anthocyanin pigments cyanidin 3- $O$-D-glucoside and cyanidin. J Agric Food Chem 42:24072410

Tsuda T, Shiga K, Ohshima K, Kawakishi S, Osawa T (1996) Inhibition of lipid peroxidation and the active oxygen radical scavenging effect of anthocyanin pigments isolated from Phaseolus vulgaris L. Biochem Pharma 52:1033-1039

Valacchi G, Rimbach G, Saliou C, Weber SU, Packer L (2001) Effect of benzoyl peroxide on antioxidant status, NF-KappaB activity and interleukinalpha gene expression in human keratinocytes. Toxicology 165:225-234

Vallance P, Leiper J (2002) Blocking NO synthesis: how, where and why? Nat Rev Drug Discov 1:939-950

Virgili F, Marino M (2008) Regulation of cellular signals from nutritional molecules: a specific role for phytochemicals, beyond antioxidant activity. Free Radic Biol Med 45:1205-1216

Vitaglione P, Donnarumma G, Napolitano A, Galvano F et al (2007) Protocatechuic acid is the major human metabolite of cyanidinglucosides. J Nutr 137:2043-2048

Wagner H, Elbl G (1992) ACE-inhibitory procyanidins from Lespedeza capitata. Planta Med 58:297

Wang J, Mazza G (2002a) Inhibitory effects of anthocyanins and other phenolic compounds on nitric oxide production in LPS/ IFN- $\alpha$-activated RAW 264.7 macrophages. J Agric Food Chem $50: 850-857$ 
Wang J, Mazza G (2002b) Quantification of nitrite in the presence of anthocyanins using Griess and GC/Ms assays. J Food Biochem 26:339-354

Wang H, Cao G, Prior RL (1997) Oxygen radical absorbing capacity of anthocyanins. J Agric Food Chem 45:304-309

Wille PR, Ribeiro-do-Valle RM, Simoes CM, Gabilan NH, Nicolau M (2001) Effect of quercetin on tachykinin-induced plasma extravasation in rat urinary bladder. Phytother Res 15:444-446
Wu XL, Beecher GR, Holden JM, Haytowitz DB et al (2006) Concentrations of anthocyanins in common foods in the United States and estimation of normal consumption. J Agric Food Chem 54:4069-4075

Yan J-J, Jung J-S, Hong Y-J, Moon YS et al (2004) Protective effect of protocatechuic acid isopropyl ester against murine models of sepsis: inhibition of TNF- $\alpha$ and nitric oxide production and augmentation of IL-10. Biol Pharmacol Bull 27:2024-2027 